\title{
Corticosteroid Sparing Agents in Frequent Relapsing and Steroid Dependent Nephrotic Syndrome in Children: A Single Center Retrospective Study
}

Bashair Alabbasi ( $\sim$ b.h.alabbasi@hotmail.com )

Prince Sultan Military Medical City

Naif Abdulmajeed

Prince Sultan Military Medical City

Abdulmonem Alghamdi

Prince Sultan Military Medical City

Saeed Alzahrani

Prince Sultan Military Medical City

Saeed Alghwery

Prince Sultan Military Medical City

Majed Aloufi

Prince Sultan Military Medical City

\section{Research Article}

Keywords: Nephrotic syndrome, Children, steroid-sparing agents, cyclosporine remission, replapses

Posted Date: August 24th, 2021

DOl: https://doi.org/10.21203/rs.3.rs-763201/v1

License: (c) (i) This work is licensed under a Creative Commons Attribution 4.0 International License. Read Full License 


\title{
Corticosteroid sparing agents in Frequent Relapsing and Steroid Dependent Nephrotic Syndrome in children: a single center retrospective study
}

\author{
Bashair Alabbasi ${ }^{1}$, Naif Abdulmajeed ${ }^{1}$, Abdulmonem Alghamdi ${ }^{1}$, Saeed Alzahrani ${ }^{1}$, Saeed \\ Alghwery $^{1}$, Majed Aloufi ${ }^{1,2}$ \\ 1 Pediatric Nephrology Department, Prince Sultan Military Medical City, Riyadh, Saudi Arabia \\ 2 College of Medicine, Alfaisal University, Riyadh, Saudi Arabia
}

\begin{abstract}
Background: Children with frequently relapsing nephrotic syndrome (FRNS) or Steroid-dependent nephrotic syndrome (SDNS) may be prescribed non-corticosteroid immunosuppressive agents whenever there is a failure to maintain remission with low-dose alternate-day prednisone and/or significant adverse effects of prednisone develop. A wide variety of immunosuppressive agents have been used in these patients to reduce the number of relapses and maintain remission.
\end{abstract}

Objective: to evaluate the outcome of Steroid sparing agents in the management of FRNS and SDNS in children with nephrotic syndrome.

Patients and methods: A retrospective study was conducted on all steroid-sensitive nephrotic syndrome (SSNS) children (1-11 years) who received any type of second line agents (e.g. CNI, MMF, cyclophosphamide, and Rituximab) over a period of 9 years from January 2010 to January 2019 in pediatric nephrology unit in Prince Sultan Military Medical City, Riyadh.

Results: The study included 24 patients. Their age at diagnosis ranged between 1 and 11 years with a mean of 3.8 years and standard deviation of $( \pm) 2.6$ years. During the first year of steroid therapy, relapse occurred among $87 \%$ of patients; of them, the number of relapses being 4 or more in $21.7 \%$. Regarding indication for the second line of treatment, SDNS was the most frequent reported (60.9\%), followed by 
FRNS (30.4\%). Concerning agents used in the second line, MMF ranked first (58.4\%), followed by Cyclophosphamide (33.3\%). Number of relapses after starting steroid sparing agent was more than once among $41.7 \%$ of patients. Duration of remission after starting steroid sparing agent ranged between 2 and 72 months (14 \pm 14.1$)$. Overall response to the second line of treatment was observed among majority of patients $(91.7 \%)$. Renal biopsy was performed in $45.8 \%$ of patients. Concerning side effects of steroid sparing agents, electrolytes disturbances and hypertension were reported by two $(8.3 \%)$ and one $(4.2 \%)$ patients respectively. Duration of remission was significantly longer among patients treated with cyclosporine (48 \pm 33.9 months) compared to other lines of treatment, $\mathrm{p}<0.001$. On the other hand, hypertension was only reported among patients treated with cyclosporine, $\mathrm{p}=0.003$.

Conclusion: The overall response of children with SDNS and FRNS to the second line agents was significant, with favorable longer remission free period with Cyclosporine use with no major side effects. Our results affected by the retrospective design of the study, as well as the small sample size. Therefore larger scale study with prospective design is highly encouraged.

\section{List of abbreviations}

CNIs: Calcineurin inhibitors

MMF: Mycophenolate mofetil

NS: Nephrotic syndrome

FRNS: Frequently relapsing nephrotic syndrome

SDNS: Steroid-dependent nephrotic syndrome

SSNS: Steroid sensitive nephrotic syndrome

KDIGO: Kidney Disease Improving Global Outcomes

SPSS: Statistical Package for Social Sciences

ANOVA: One-way analysis of variance 
Keywords: Nephrotic syndrome, Children, steroid-sparing agents, cyclosporine remission, replapses

\section{INTRODUCTION}

\subsection{Background}

Nephrotic syndrome (NS) is defined by the presence of edema, proteinuria with urine protein/creatinine ratio (uPCR) of equal or more than $200 \mathrm{mg} / \mathrm{mmol}$, or $300 \mathrm{mg} / \mathrm{dl}$, or $3+$ protein on urine dipstick, and hypoalbuminemia of equal or less than $25 \mathrm{~g} / \mathrm{l}^{(1-3)}$

It is one of the commonest renal disease in children with an incidence of 1-2 per 100000 children, and a prevalence of 16 per 100000 children. ${ }^{(2,3)}$ Corticosteroids are the mainstay of treatment, with response in $85 \%-90 \%$ of children. ${ }^{(3)}$ Those are labelled as Steroid sensitive NS (SSNS). Unfortunately, most of the children with nephrotic syndrome will experience at least one relapse after their initial diagnosis, with up to half of initial steroid responders will have a frequently relapsing nephrotic syndrome (FRNS) or steroid-dependent nephrotic syndrome (SDNS). ${ }^{(3)}$ FRNS is defined as two or more relapses within six months of initial diagnosis, or four or more relapse in any twelve months

period. ${ }^{(1)}$ SDNS is defined as two consecutive relapse during steroid therapy or within fourteen days of stopping therapy. ${ }^{(1,3)}$ These children are at risk of adverse effects from prolonged and multiple steroids uses. Non-corticosteroid immunosuppressive medications are used as steroids sparing agents in order to prolong the periods of remission in these patients; however, these medications have significant potential adverse effects. Among these medications are Cyclophosphamide, Rituximab, Mycophenolate mofetil (MMF), Calcineurin inhibitors (CNIs) such as Cyclosporine and Tacrolimus. ${ }^{(2)}$ 


\section{Immunosuppressive therapy}

\section{Treatment of the initial presentation of nephrotic syndrome}

The KDIGO (Kidney Disease Improving Global Outcomes) guidelines recommend that oral prednisone to be administered as a single daily dose starting at $60 \mathrm{mg} / \mathrm{m}^{2} /$ day or $2 \mathrm{mg} / \mathrm{kg} /$ day to a maximum of $60 \mathrm{mg} /$ day to be given for 4-6 weeks followed by an alternate-day prednisone as $40 \mathrm{mg} / \mathrm{m}^{2}$ or $1.5 \mathrm{mg} / \mathrm{kg}$ (maximum $40 \mathrm{mg}$ on alternate days) and continued for 2-5 months with tapering of the $\operatorname{dose}^{(1,3)}$

\section{Steroid-sparing agents}

Children with FRNS or SDNS may be prescribed non-corticosteroid immunosuppressive agents when there is a failure to maintain remission with low-dose alternate-day prednisone and/or significant adverse effects of prednisone develop. ${ }^{(3)}$

A wide variety of immunosuppressive agents have been used in these FRNS or SDNS patients to reduce relapse and maintain remission. These agents includes; Mycophenolate mofetil (MMF), Cyclophosphamide, Calcineurin inhibitors (GNIs) (e.g. Tacrolimus or Cyclosporine), and Rituximab. ${ }^{(2)}$ Cyclophosphamide (alkylating chemotherapeutic agent) remains the most commonly used steroid-sparing agent, in part due to the possibility of achieving a prolonged period of disease-free remission. ${ }^{(3)}$ The Calcineurin inhibitors (CNIs) are similarly effective at achieving remission. ${ }^{(3)}$ However, the use of alkylating agents and CNIs is limited by their side-effects, such as bone marrow suppression and gonadal toxicity of alkylating agent, and nephrotoxicity of GNIs.

In recent years, MMF has been used as a steroid-sparing agent due to a favorable side-effects profile, though it may be less effective than CNIs. ${ }^{(3)}$

Rituximab is a monoclonal antibody directed toward the CD-20 antigen expressed on pre-B and 
mature B-lymphocytes, but not on Plasma cells. ${ }^{(3)}$ Initially it was developed for B-cell lymphomas, it is now also used in the treatment of autoimmune disorders, as well as FRNS and SDNS, and it may facilitate the withdrawal of other immunosuppressive agents. ${ }^{(3)}$

\subsection{Objectives}

This study aims to evaluate the outcome of Steroid sparing agents (CNIs, MMF, Cyclophosphamide, and Rituximab) in the management of FRNS and SDNS in children.

The specific objective is to recognize which of the steroid sparing agents will have:

1- Less number of relapses and maintaining longer remission periods in the management of FRSN/SDNS.

2- Lowest possible side effects (either from steroids or steroid sparing agents) that can be achieved in the management of FRSN/SDNS.

\subsection{Literature review}

Alkylating agents such as cyclophosphamide have been used for over 40 years in patients with steroid-sensitive nephrotic syndrome (SSNS) presenting with frequent relapses (FRNS) or steroid dependence (SDNS). ${ }^{(4)}$ However, the use of cyclophosphamide is limited nowadays due to its severe and undesirable side effects, especially with the availability of newer classes of drugs with different mechanisms and has more tolerable side effects. One of the major concerns with regard to the use of alkylating agents such as cyclophosphamide in children and adolescents is gonadotoxicity. CNIs and MMF were initially used as immune-suppressants for prevention of organ transplant rejection. Recent studies have confirmed 
the important role of CNIs and MMF in the treatment of relapsing steroid-sensitive nephrotic syndrome, both FRNS and SDNS. The overwhelming majority of clinical trials evaluating CNIs therapy in FSGS and MCD patients used cyclosporine; however, most authorities believe that cyclosporine and Tacrolimus are interchangeable, and preferably use Tacrolimus in girls because this drug is associated with fewer cosmetic side effects. In most of the studies, MMF has been shown to result in statistically significant reduction in frequency of relapses as well as the cumulative dose of steroids required, irrespective of the previous alternative drugs used.(2)

Rituximab is of major importance in multiple drug-dependent SSNS, but many questions regarding the dosing, repetition and long-term side effects remain unanswered. The first studies which report the benefits of rituximab in idiopathic NS were published in the early 2000's and initially consisted of case reports and small case series (ranging from 1 to 24 patients) with SDNS or FRNS.(2) These studies showed signficant responses to Rituximab, often with prolonged remission, with many children being able to be weaned off the immunosuppressive drugs. Despite this, the 2012 KDIGO Glomerulonephritis Guidelines did not strongly endorse the use of rituximab in FRNS or SDNS, since there were no good randomized studies or clinical trials to evaluate its benefits at that time. ${ }^{(2)}$

\section{PATIENTS AND METHODS}

A retrospective study was conducted on all steroid-sensitive nephrotic syndrome (SSNS) children who received any type of second line agents (e.g. GNI, MMF, cyclophosphamide, or Rituximab) over a period of 9 years from January 2010 to January 2019 in Prince Sultan Military Medical City, Riyadh.

The data were collected from patients with FRNS or SDNS who attended the pediatric nephrology clinics. All the patients' data were taken from their medical records including patient age, 
gender, weight, height, year of diagnosis, number of relapses, the immunosuppressant agents (dose, duration of therapy) which wERE used and its effect on the number of relapses and remission periods thereafter.

All the data were screened by the principal investigators (providing patients' privacy and confidentiality are protected) with standardized data collections methods. Any missing or incomplete data outcomes were addressed accordingly.

$\underline{\text { Inclusion criteria }}$

All children aged from 2 to 14 years with FRNS or SDNS. Relapse of nephrotic syndrome is defined by recurrence of proteinuria as detected either by urine dipstick of equal or more than $3+$ protein or by protein to creatinine ratio of equal or more than $200 \mathrm{mg} / \mathrm{mmol}$. The definitive diagnosis by renal biopsy is not required. ${ }^{(1,5)}$

$\underline{\text { Exclusion criteria }}$

Children with their first episode of nephrotic syndrome, children with other types of nephrotic syndrome (e.g. congenital nephrotic syndrome, steroid resistant nephrotic syndrome). ${ }^{(5)}$ Also, any patient with systemic diseases, such as system lupus erythrematosis (SLE), Henoch Schonlein purpura, or hepatitis B virus (HBV) related nephropathy. ${ }^{(6)}$

\section{$\underline{\text { Ethical considerations }}$}

Approval of the research proposal has been obtained from the local Research and ethical committee, Prince Sultan Military Medical City, Riyadh city. The research was a chart review and it was not containing any confidential patient information or questionnaire. So, consents were not required. 
$\underline{\text { Statistical Analyses: }}$

Descriptive statistics, including means \pm standard deviation for quantitative continuous variables and frequency, percentage for categorical variables were computed. All data were analyzed by using IBM SPSS, version 25. Inferential statistics were done using chi-square test to investigate for the association between two categorical variables and one-way analysis of variance test (ANOVA) to compare means of a continuous variable between more than two different groups. A P value $<0.05$ was considered statistically significant.

\section{Results}

The study included 24 patients. Their age at diagnosis ranged between 1 and 11 years with a mean of 3.8 years and standard deviation of $( \pm) 2.6$ years. Majority were males $(79.2 \%)$. Their weight at the start of treatment ranged between 10.3 and $35.5 \mathrm{Kg}(17.0 \pm 5.2)$ whereas current weight ranged between 17.5 and $95 \mathrm{Kg}(48.5 \pm 19.5)$. Their height at start of treatment ranged between 88 and $141 \mathrm{~cm}$

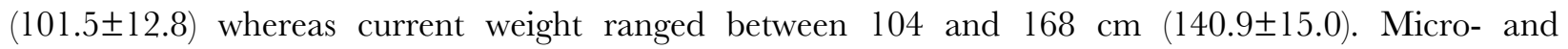
macro-hematuria were reported among $30.4 \%$ and $4.3 \%$ of patients, respectively. Hypertension was present among $8.7 \%$ of patients at presentation. Serum creatinine level at presentation ranged between 17

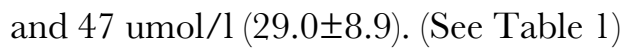


Table 1: Basic characteristics of the participants $(n=24)$

\begin{tabular}{|c|c|}
\hline $\begin{array}{l}\text { Current age (years) } \\
\text { Range } \\
\text { Mean } \pm \text { SD }\end{array}$ & $\begin{array}{l}4-21 \\
13.2 \pm 4.9\end{array}$ \\
\hline $\begin{array}{l}\text { Age at diagnosis (years) } \\
\text { Range } \\
\text { Mean } \pm \mathrm{SD}\end{array}$ & $\begin{array}{l}1-11 \\
3.8 \pm 2.6\end{array}$ \\
\hline $\begin{array}{l}\text { Gender } \\
\text { Males }(\mathrm{N} ; \%) \\
\text { Females }(\mathrm{N} ; \%)\end{array}$ & $\begin{array}{l}19 ; 79.2 \% \\
5 ; 20.8 \%\end{array}$ \\
\hline $\begin{array}{l}\text { Weight at start of treatment }(\mathbf{K g})(\mathbf{n}=\mathbf{2 2}) \\
\text { Range } \\
\text { Mean } \pm \text { SD }\end{array}$ & $\begin{array}{l}10.3-35.5 \\
17.0 \pm 5.2\end{array}$ \\
\hline $\begin{array}{l}\text { Height at start of treatment }(\mathbf{c m})(\mathbf{n}=\mathbf{2 2}) \\
\text { Range } \\
\text { Mean } \pm \text { SD }\end{array}$ & $\begin{array}{l}88-141 \\
101.2 \pm 12.8\end{array}$ \\
\hline $\begin{array}{l}\text { Current weight }(\mathbf{K g})(\mathbf{n}=\mathbf{2 3}) \\
\text { Range } \\
\text { Mean } \pm \text { SD }\end{array}$ & $\begin{array}{l}17.5-95 \\
48.5 \pm 19.5\end{array}$ \\
\hline $\begin{array}{l}\text { Gurrent height }(\mathbf{c m})(\mathbf{n}=\mathbf{2 3}) \\
\text { Range } \\
\text { Mean } \pm S D\end{array}$ & $\begin{array}{l}104-168 \\
140.9 \pm 15.0\end{array}$ \\
\hline Micro-hematuria at presentation $(\mathbf{N} ; \%)(n=23)$ & $7(30.4)$ \\
\hline Macro-hematuria at presentation $(\mathbf{N} ; \%)(n=23)$ & $1(4.3)$ \\
\hline Hypertension at presentation $(\mathrm{N} ; \%)(\mathrm{n}=23)$ & $2(8.7)$ \\
\hline $\begin{array}{l}\text { Serum creatinine at presentation }(\text { umol/1) }(\mathbf{n}=\mathbf{2 3}) \\
\text { Range } \\
\text { Mean } \pm \text { SD }\end{array}$ & $\begin{array}{l}17-47 \\
29.0 \pm 8.9\end{array}$ \\
\hline
\end{tabular}




\section{Initial steroid therapy}

Table 2 shows that the duration of initial steroid therapy ranged between 4 and 6 months (4.5 \pm 0.6$)$. The dose was $60 \mathrm{mg} / \mathrm{m}^{2} /$ day. Time to initial response ranged between 4 and 14 days $(8.2 \pm 2.4)$. During the first year of therapy, relapse occurred among $87 \%$ of patients; of those who relapsed $(87 \%)$ the number of relapses being 4 or more occurred in $21.7 \%$, while relapses which occurred less than 4 accounted for $65.3 \%$. Relapses during weaning of initial steroid therapy were observed among $21.7 \%$ of patients. Time to relapse after initial steroid therapy ranged between one and 12 months $(6.4 \pm 3.1)$.

Table 2: Profile of initial steroid therapy among the participants $(n=24)$

\begin{tabular}{|c|c|}
\hline $\begin{array}{l}\text { Duration of initial steroid therapy (months) }(\mathbf{n}=\mathbf{2 1}) \\
\text { Range } \\
\text { Mean } \pm \text { SD }\end{array}$ & $\begin{array}{l}4-6 \\
4.5 \pm 0.6\end{array}$ \\
\hline $\begin{array}{l}\text { Dose of initial steroid therapy }(\mathbf{m g})(\mathbf{n}=22) \\
\text { Range } \\
\text { Mean } \pm \text { SD }\end{array}$ & $\begin{array}{l}20-70 \\
36.7 \pm 10.2\end{array}$ \\
\hline $\begin{array}{l}\text { Time to initial response to steroid therapy (days) }(\mathbf{n}=\mathbf{2 2}) \\
\text { Range } \\
\text { Mean } \pm \mathrm{SD}\end{array}$ & $\begin{array}{l}4-14 \\
8.2 \pm 2.4\end{array}$ \\
\hline $\begin{array}{l}\text { Number of relapses in the first } 6 \text { months }(\mathbf{N} ; \%)(\mathbf{n}=22) \\
\text { No } \\
\text { Once } \\
\text { Twice }\end{array}$ & $\begin{array}{l}12 ; 54.5 \% \\
6 ; 27.3 \% \\
4 ; 18.2 \%\end{array}$ \\
\hline $\begin{array}{l}\text { Number of relapses per year }(\mathbf{N} ; \%)(\mathbf{n}=23) \\
<4 \\
\geq 4\end{array}$ & $\begin{array}{l}6 ; 26 \% \\
17: 74 \%\end{array}$ \\
\hline $\begin{array}{l}\text { Relapses during weaning of initial steroid therapy }(\mathbf{N} ; \%) \\
(\mathbf{n}=\mathbf{2 3}) \\
\text { No } \\
\text { Yes }\end{array}$ & $\begin{array}{l}18 ; 78.3 \% \\
5 ; 21.7 \%\end{array}$ \\
\hline $\begin{array}{l}\text { Time to relapse after initial steroid therapy }(\text { months })(\mathbf{n}=\mathbf{2 3}) \\
\text { Range } \\
\text { Mean } \pm \mathrm{SD}\end{array}$ & $\begin{array}{l}1-12 \\
6.4 \pm 3.1\end{array}$ \\
\hline
\end{tabular}




\section{Second line of treatment}

Regarding indication for the second line of treatment, SDNS was the most frequent reported $(60.9 \%)$, followed by FRNS $(30.4 \%)$. Concerning agents used in the second line, MMF ranked first (58.4\%), followed by Cyclophosphamide (33.3\%). Duration of steroid sparing therapy ranged between 3 and 84 months (18.4 \pm 21.8$)$. Number of relapses after starting steroid sparing agent was more than once among $41.7 \%$ of patients. Duration of remission after starting steroid sparing agent ranged between 2 and 72 months (14 \pm 14.1$)$. Time from diagnosis to start second line ranged between 0 to 14 years $(3.7 \pm 3.9)$ as

some patients had been diagnosed as SDNS/FRNS in the first year after diagnosis. Dose of concurrent steroid with second line was $5 \mathrm{mg}$ every other day and $5 \mathrm{mg}$ once daily in $33.3 \%$ and $20.8 \%$ of patients, respectively. Overall response to the second line of treatment was observed among majority of patients $(91.7 \%)$ as clear from Figure 1. 
Table 3: Profile of second line of treatment among the participants $(\mathbf{n}=24)$

\begin{tabular}{|c|c|}
\hline $\begin{array}{l}\text { Indications for the second line of treatment }(\mathbf{N} ; \mathbf{\%})(\mathbf{n}=\mathbf{2 3}) \\
\text { FRNS } \\
\text { SDNS } \\
\text { Both }\end{array}$ & $\begin{array}{l}7 ; 30.4 \% \\
14 ; 60.9 \% \\
2 ; 8.7 \%\end{array}$ \\
\hline $\begin{array}{l}\text { Second line agent } \\
\text { MMF } \\
\text { Cyclophosphamide } \\
\text { Gyclosporin } \\
\end{array}$ & $\begin{array}{l}14 ; 58.4 \% \\
8 ; 33.3 \% \\
2 ; 8.3 \%\end{array}$ \\
\hline $\begin{array}{l}\text { Duration of steroid sparing (months) } \\
\text { Range } \\
\text { Mean } \pm \mathrm{SD}\end{array}$ & $\begin{array}{l}3-84 \\
18.4 \pm 21.8\end{array}$ \\
\hline $\begin{array}{l}\text { Number of relapses after starting steroid sparing agent }(\mathbf{N} ; \%) \\
0 \\
1 \\
2 \\
3\end{array}$ & $\begin{array}{l}5 ; 20.8 \% \\
9 ; 37.5 \% \\
9 ; 37.5 \% \\
1 ; 4.2 \%\end{array}$ \\
\hline $\begin{array}{l}\text { Duration of remission after starting steroid sparing agent (months) } \\
\text { Range } \\
\text { Meean } \pm \mathrm{SD}\end{array}$ & $\begin{array}{l}2-72 \\
14.0 \pm 14.1 \\
\end{array}$ \\
\hline $\begin{array}{l}\text { Time from diagnosis to start second line (years) } \\
\text { Range } \\
\text { Meean } \pm \mathrm{SD}\end{array}$ & $\begin{array}{l}0-14 \\
3.7 \pm 3.9\end{array}$ \\
\hline $\begin{array}{l}\text { Dose of concurrent steroid with second line }(\mathbf{N} ; \%) \\
3 \text { EOD } \\
5 \text { EOD } \\
5 \text { OD } \\
10 \text { EOD } \\
10 \text { OD } \\
15 \text { EOD } \\
30 \text { EOD } \\
39 \text { OD }\end{array}$ & $\begin{array}{l}1 ; 4.2 \% \\
8 ; 33.3 \% \\
5 ; 20.8 \% \\
3 ; 12.5 \% \\
1 ; 4.2 \% \\
2 ; 8.3 \% \\
3 ; 12.5 \% \\
1 ; 4.2 \%\end{array}$ \\
\hline
\end{tabular}

EOD: Every other day OD: Once daily 


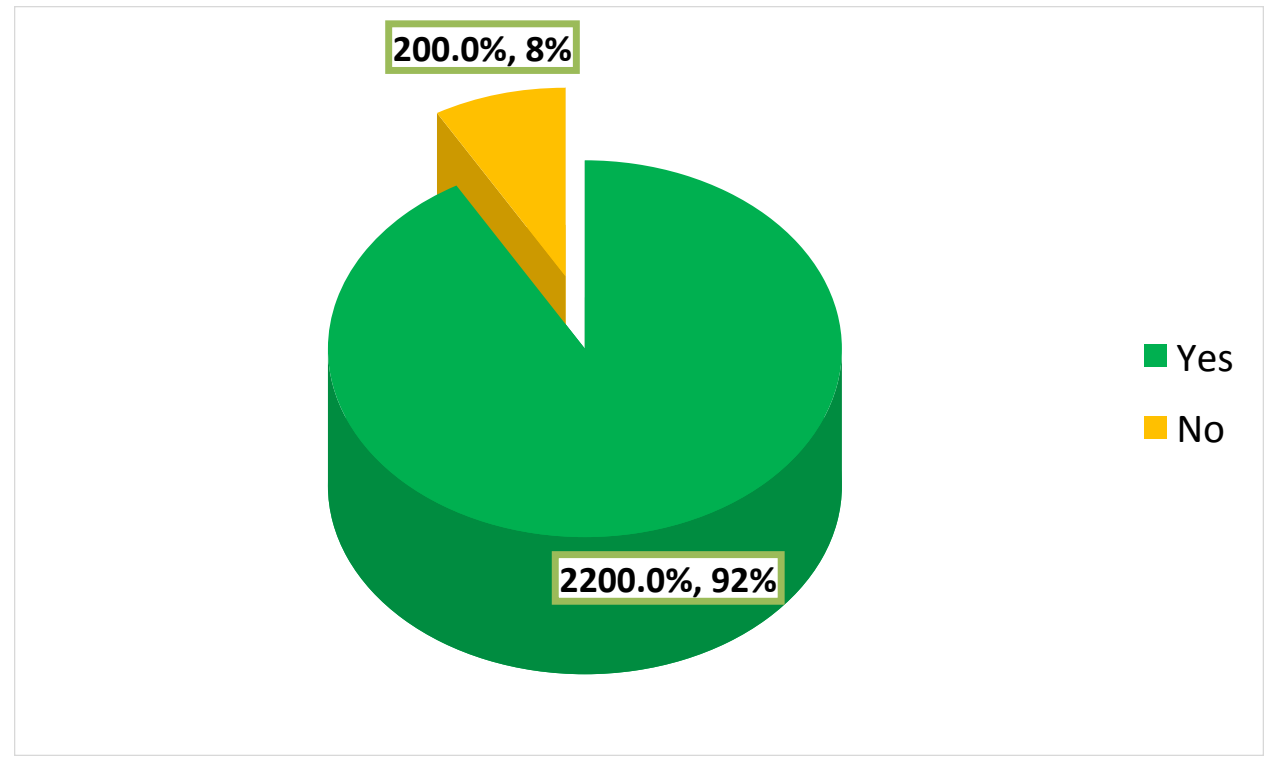

Figure 1: Overall response to the second line of treatment 
Diagnosis of nephrotic syndrome

SDNS represent almost two-thirds of nephrotic syndrome cases (62.5\%) whereas FRNS represent $16.7 \%$ and both types represent $20.8 \%$ of them as illustrated in Figure 2.

\section{Renal biopsy}

Renal biopsy was performed in $45.8 \%$ of patients (Figure 3). Renal biopsy was done $45.4 \%$ and $36.4 \%$ of children with SDNS and FRNS. Figure 4

Side effects of the second line of treatment

Figure 5 shows that electrolytes disturbances and hypertension were reported by two $(8.3 \%)$ and one $(4.2 \%)$ patients on second line of therapy, respectively. 


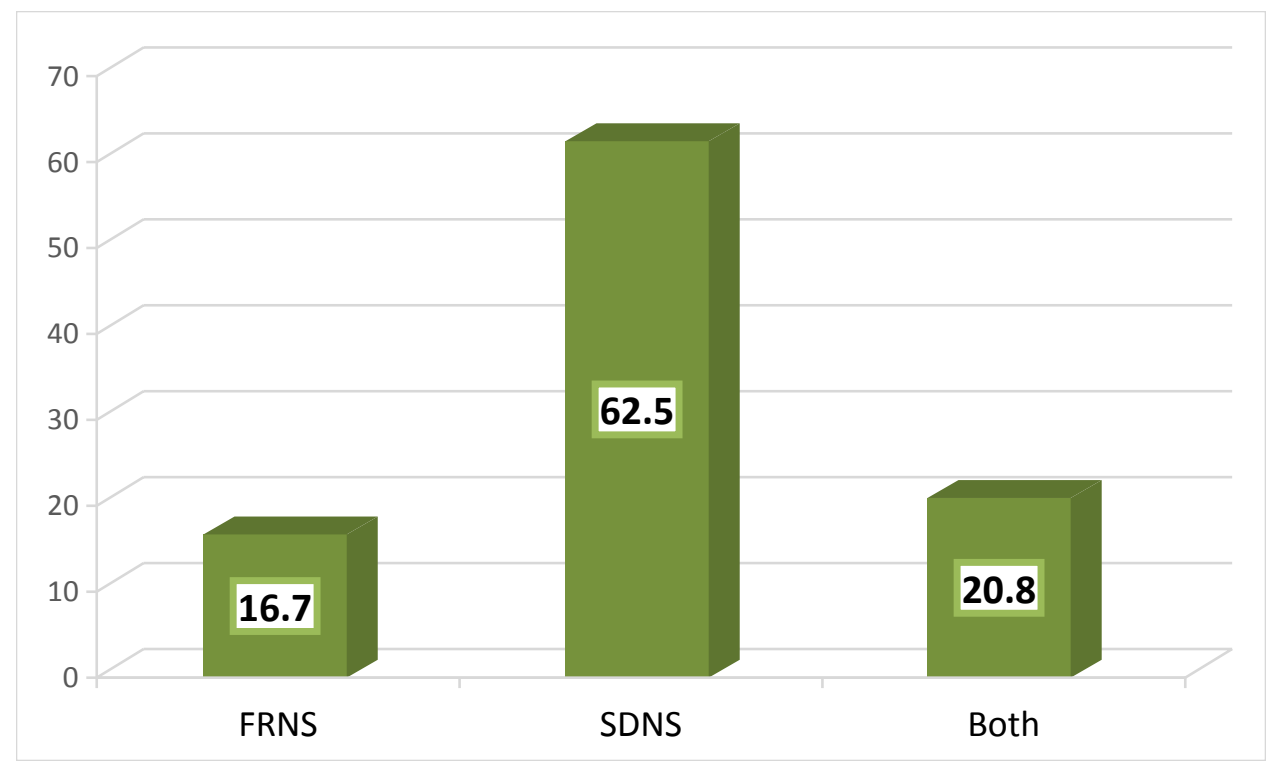

Figure 2: Diagnosis of nephrotic syndrome

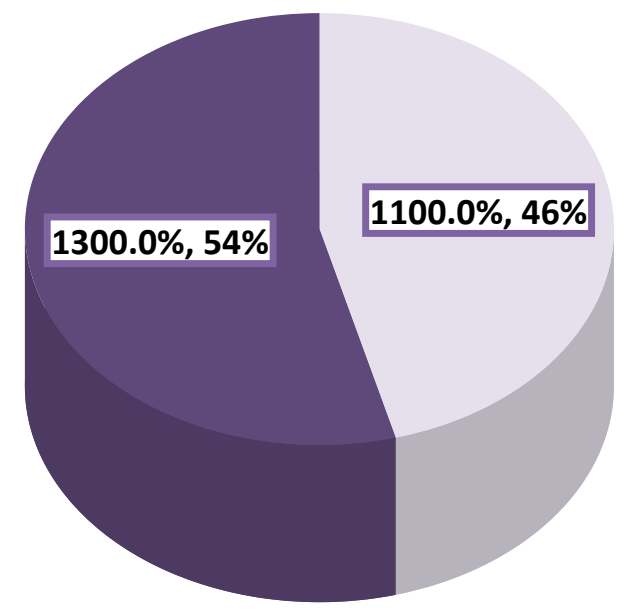

Yes

No

Figure 3: History of renal biopsy among children with nephrotic syndrome $(n=24)$ 


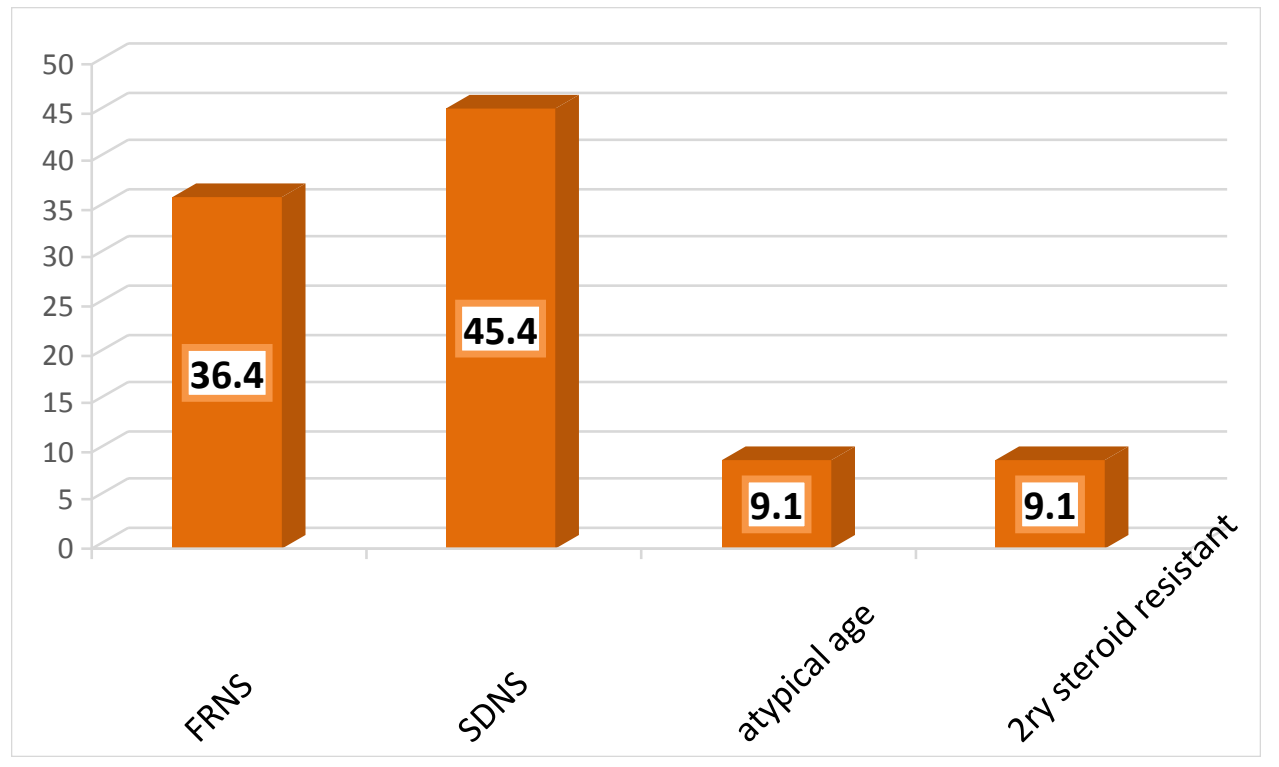

Figure 4: Indication for renal biopsy among children with nephrotic syndrome $(\mathbf{n}=11)$

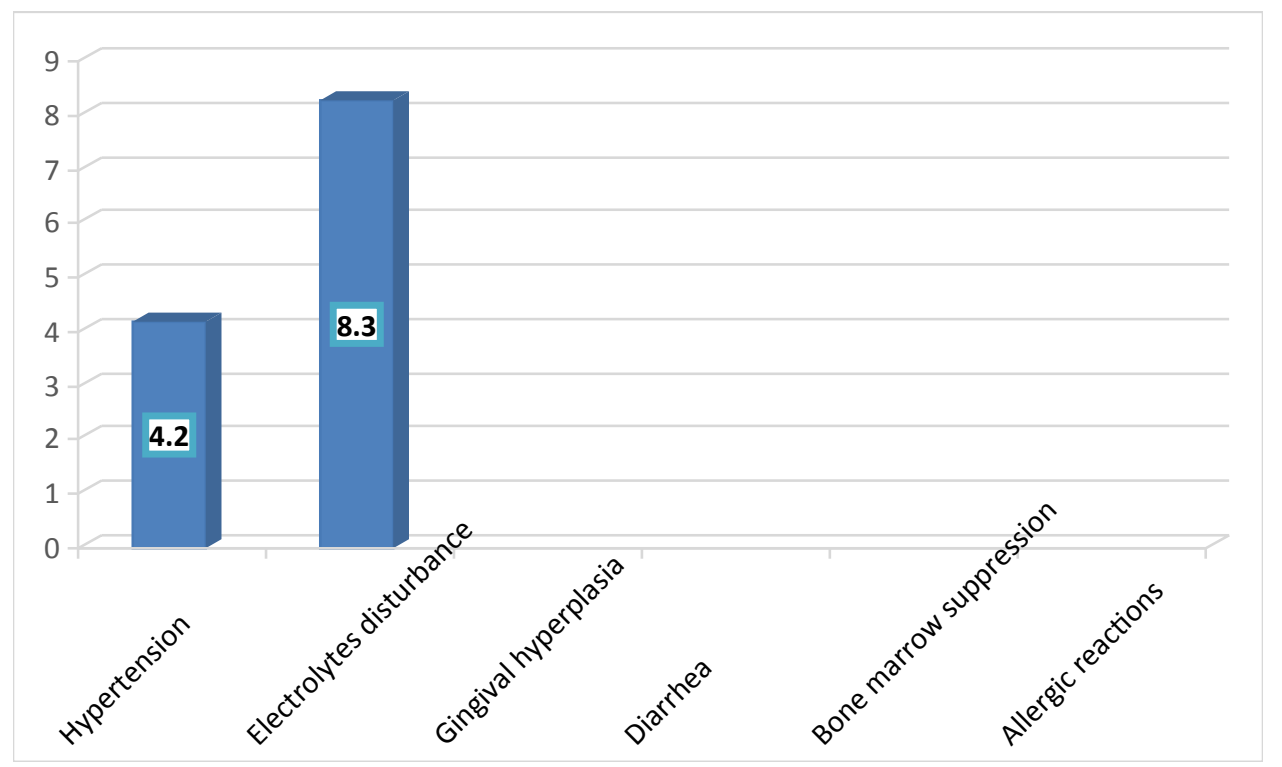

Figure 5: Side effects after the second line of treatment of children with nephrotic syndrome 


\section{Comparison between different agents used in second line treatment}

Duration of remission was significantly longer among patients treated with cyclosporine $(48 \pm 33.9$ months) compared to other lines of treatment, $\mathrm{p}<0.001$. On the other hand, hypertension was only reported among patients treated with cyclosporine, $\mathrm{p}=0.003$. Number of relapses, electrolytes disturbance and overall response were not significantly associated with the type of treatment steroid sparing agent.

Table 4 
Table 4: Comparison between different agents used in second line of nephrotic syndrome treatment

\begin{tabular}{|c|c|c|c|c|}
\hline & $\begin{array}{l}\text { MMF } \\
\mathbf{N}=14 \\
\mathbf{N}(\%)\end{array}$ & $\begin{array}{c}\text { Cyclophosphamide } \\
\mathbf{N}=8 \\
\mathbf{N}(\%)\end{array}$ & $\begin{array}{c}\text { Cyclosporin } \\
\mathbf{N}=2 \\
\mathbf{N}(\%)\end{array}$ & p-value \\
\hline $\begin{array}{l}\text { Number of relapses after } \\
\text { starting steroid sparing } \\
\text { agent } \\
0(\mathrm{n}=5) \\
1(\mathrm{n}=9) \\
2(\mathrm{n}=9) \\
3(\mathrm{n}=1)\end{array}$ & $\begin{array}{l}4(28.6) \\
3(21.4) \\
6(42.9) \\
1(7.1)\end{array}$ & $\begin{array}{c}0(0.0) \\
5(62.5) \\
3(37.5) \\
0(0.0)\end{array}$ & $\begin{array}{l}1(50.0) \\
1(50.0) \\
0(0.0) \\
0(0.0)\end{array}$ & $0.336^{*}$ \\
\hline $\begin{array}{l}\text { Duration of remission } \\
\text { after starting } \quad \text { steroid } \\
\text { sparing agent (months) } \\
\text { Mean } \pm \mathrm{SD}\end{array}$ & $11.5 \pm 7.7^{\mathrm{\sharp}}$ & $10 \pm 4.3^{\mathrm{r}}$ & $48 \pm 33.9^{\mathrm{Hr}}$ & $<0.001 * *$ \\
\hline $\begin{array}{l}\text { Electrolyte disturbance } \\
(n=2)\end{array}$ & $1(7.1)$ & $0(0.0)$ & $1(50.0)$ & $0.071^{*}$ \\
\hline Hypertension $(n=1)$ & $0(0.0)$ & $0(0.0)$ & $1(50.0)$ & $0.003^{*}$ \\
\hline $\begin{array}{l}\text { Overall response } \\
\text { No }(\mathrm{n}=2) \\
\text { Yes }(\mathrm{n}=12)\end{array}$ & $\begin{array}{c}2(14.3) \\
12(85.7)\end{array}$ & $\begin{array}{l}0(0.0) \\
8(100)\end{array}$ & $\begin{array}{l}0(0.0) \\
2(100)\end{array}$ & 0.459 \\
\hline
\end{tabular}

* Chi-square test ** ANOVA test

${ }^{ } \mathbf{P}<0.001$ (Turkey`s test between $\mathrm{MMF}$ and cycloporin)

${ }^{\text {P }}<0.001$ (Turkey`s test between cyclophosphamide and cycloporin) 


\section{Third line of treatment}

From Table 3, it is obvious that the indications for the third line of treatment was mainly FRNS

(63.6\%), followed by SDNS (36.4\%). The main agents were MMF (45.5\%), Rituximab (18.2\%) and Cyclosporin (18.2\%). Duration of third line therapy ranged between 1 and 5 years $(3.2 \pm 1.7)$.

There was no statistically significant association between type of third line treatment agent and response to therapy as shown in Table 6 .

Table 5: Profile of second line of treatment among the participants $(n=11)$

\begin{tabular}{|l|l|}
\hline Indication $(\mathrm{N} ; \%)$ & $7 ; 63.6 \%$ \\
FRNS & $4 ; 36.4 \%$ \\
SDNS & \\
\hline Third line agent $(\mathrm{N} ; \%)$ & $5 ; 45.6 \%$ \\
MMF & $2 ; 18.2 \%$ \\
Rituximab & $2 ; 18.2 \%$ \\
Cyclosporin & $2 ; 19.0$ \\
Tacrolimus & \\
\hline Duration of steroid sparing (years) $(\mathbf{n}=\mathbf{1 1}) *$ & $1-5$ \\
Range & $3.2 \pm 1.7$ \\
Mean \pm SD 2 & \\
\hline
\end{tabular}

*One patient had 2 doses and one had 4 doses and one had two years and still ongoing 


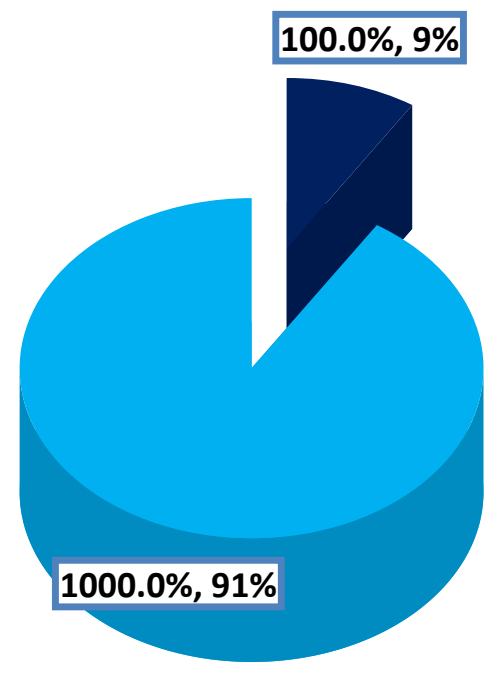

No

Yes

Figure 6: Response of children with nephrotic syndrome to the third line of treatment $(n=11)$

Table 6: Comparison between different agents used in third line of nephrotic syndrome treatment regarding response to treatment

\begin{tabular}{|l|c|c|c|c|c|}
\hline & $\begin{array}{c}\text { MMF } \\
\mathbf{N = 5}\end{array}$ & $\begin{array}{c}\text { Rituximab } \\
\mathbf{N = 2} \\
\mathbf{N}(\%)\end{array}$ & $\begin{array}{c}\text { Cyclosporin } \\
\mathbf{N}(\%)\end{array}$ & $\begin{array}{c}\text { Tacrolimus } \\
\mathbf{N}=\mathbf{2}\end{array}$ & p-value* \\
\hline Overall & & & & & \\
response & & & & & \\
No (n=1) & $0(0.0)$ & $0(0.0)$ & $1(50.0)$ & $0(0.0)$ & \\
Yes $(\mathrm{n}=11)$ & $5100)$ & $2(100)$ & $1(50.0)$ & $2(100)$ & 0.175 \\
\hline
\end{tabular}

* Chi-square test 


\section{Discussion}

Although, majority of children with nephrotic syndrome respond to steroid therapy, a considerable percentage of them i.e. up to $70 \%$ reported relapses. ${ }^{(7)}$ Higher percentage of initial replaces were observed in the present study as during the first year of steroid therapy, relapse occurred among $87 \%$ of patients; of them, the number of relapses being 4 or more in $21.7 \%$ and time to relapse after initial steroid therapy ranged between one and 12 months $(6.4 \pm 3.1)$.

In an old study, Tarshish et al (1997) reported that half of relapses after steroid therapy were due to steroid-sensitive nephrotic syndrome (SSNS) where relapses occur in a frequency of more than 2 relapses in 6 months or $>4$ relapses within 1 year. $^{(8)}$

Some patients became steroid dependent and experienced relapse in two weeks with decreasing or cessation of the steroid dose. ${ }^{(8,9)}$ In the present study, the indications for starting the second line of treatment after initial steroid therapy were SDNS (60.9\%), and FRNS (30.4\%).

It has been documented that corticosteroids use in nephrotic children with relapsing SSNS, SDNS or SRNS can lead to severe side effects; therefore, other therapeutic options are needed to prevent corticosteroid toxicity (second line of treatment). ${ }^{(10,11)}$ The pathogenesis of relapsing SSNS, SRNS and SDNS is not clearly understood; however, immunological factors may have a role, therefore, the utilization of immunological treatment and immunosuppressant's have shown good results. ${ }^{(12)}$

Concerning agents used in the second line of treatment in the present study, MMF ranked first (58.4\%), followed by Cyclophosphamide (33.3\%). Duration of steroid sparing therapy ranged between 3 and 84 months (18.4 \pm 21.8$)$. Number of relapses after starting steroid sparing agent was more than once among $41.7 \%$ of patients whereas duration of remission after starting steroid sparing agent ranged 
between 2 and 72 months (14 \pm 14.1$)$. Time from diagnosis to start second line ranged between 0 to 14 years $(3.7 \pm 3.9)$ as some patients had been diagnosed as SDNS/FRNS in the first year after diagnosis. Dose of concurrent steroid with second line was $5 \mathrm{mg}$ every other day and $5 \mathrm{mg}$ once daily in $33.3 \%$ and $20.8 \%$ of patients, respectively. Overall response to the second line of treatment was observed among majority of patients $(91.7 \%$ ). In a recent systematic review and metaanalysis included 24 trials and 1062 patients, chlorambucil, rituximab, and cyclophosphamide were more effective in terms of relapse rate and adverse effects than azathioprine and levamisole, but, levamisole, and azathioprine were better tolerated than rituximab, cyclophosphamide and chlorambucil at 6 months, and rituximab, vincristine, levamisole, and MMF were more tolerable than cyclosporine, chlorambucil, and cyclophosphamide at 12 months, while at 24 months, levamisole, chlorambucil, and cyclophosphamide were more effective than vincristine and cyclosporine, while vincristine, levamisole, and chlorambucil were more tolerable than cyclosporine and cyclophosphamide. ${ }^{(13)}$

Regarding, comparison between different agents used in the second line of treatment, the present study revealed that duration of remission was significantly longer among patients treated with

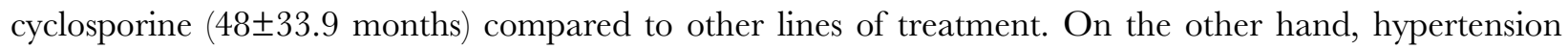
was only reported among patients treated with cyclosporine. Fu H-D, et al (2016) observed that mycophenolate mofetil agent had the greatest odds of relapse opposed to tacrolimus, cyclophosphamide or cyclosporine, and cyclophosphamide had the lowest relapse rate, and tacrolimus ranked second one with respect to relapse. ${ }^{(7)}$ Durkan et al (2001) in their study with 17 randomized controlled trials (RCTs) revealed a significant reduction in relapse rate at 6-12 months with cyclophosphamide and chlorambucil therapy compared with prednisolone alone. ${ }^{(10)}$ Pravitsitthikul et al observed that alkylating agents (cyclophosphamide and chlorambucil) lead to greater reduction in risk of relapse at 6-12 months and 
12-24 months than prednisolone alone while the risk of relapse at 2 years was similar between chlorambucil and cyclophosphamide. And they revealed also that cyclosporine was as effective as cyclophosphamide and chlorambucil. ${ }^{(14)}$ Other different findings were also reported by others. ${ }^{(15-17)}$ The non consensus between different studies, including the present one could reflect the variability of the decision regarding the most appropriate second-line agent for treating children with nephrotic syndrome.

It is obvious from the present study that the main indications for the third line of treatment were FRNS $(63.6 \%)$ and SDNS $(36.4 \%)$. Regarding the agents used in the third line of treatment, MMF ranked first, (45.5\%), followed by Rituximab (18.2\%) and Cyclosporin (18.2\%). The current study revealed no statistically significant association between type of third line treatment agent and response to therapy. We could not find similar studies in this regards for comparison.

Limitations of the present study include the small sample size which might under-power the results to detect a significant associations. Therefore, caution is warranted in interpreting our results. Second, the study was carried out in only one healthcare facility which affects the ability to generalize the results over other healthcare facilities in Riyadh, Saudi Arabia. Finally, its design as a retrospective cohort study depending for getting information on the accuracy of medical records is considered another limitation of the study. Despite of those limitations, this study could be considered as an important study to evaluate the outcome of Steroid sparing agents in the management of FRNS and SDNS in children with nephrotic syndrome.

In conclusion, the overall response of children with SDNS and FRNS to the second line agents was significant, with favorable longer remission free period with Cyclosporine use with no major side effects. Our results affected by the retrospective design of the study, as well as the small sample size. Therefore larger scale study with prospective design is highly encouraged. 


\section{Declarations}

Abbreviations:

NS: nephrotic syndrome

SDNS: steroids dependent nephrotic syndrome

FRNS: Frequently relapsing nephrotic syndrome

SSNS: Steroid sensitive nephrotic syndrome

FSGS: focal segmental glomerulosclerosis

MCD: minimal change disease

CNIs: Calcineurin inhibitors

MMF: Mycophenolate mofetil

KDIGO: Kidney Disease Improving Global Outcomes

SPSS: Statistical Package for Social Sciences

ANOVA: One-way analysis of variance

Ethics approval and consent to participate: this paper has approval of the research ethics committee in prince sultan military medical city Consent for publication: Not applicable

Availability of data and material: The datasets used and/or analysed during the current study available from the corresponding author on reasonable request.

Competing interests: not applicable

Funding: No funding was obtained for this study.

Authors' contributions: all authors contributed in writing and reviewing the manuscript

Acknowledgements: not applicable

\section{References}

1. Beck L, Bomback AS, Choi MJ, Holzman LB, Langford C, Laura H Mariani LH, et al. KDOQI US commentary on the 2012 KDIGO clinical practice guideline for glomerulonephritis. Am J Kidney Dis. 2013 Sep;62(3):403-41. doi: 10.1053/j.ajkd.2013.06.002

2. Kallash M, Smoyer WE, Mahan JD. Rituximab Use in the Management of Childhood Nephrotic Syndrome. Front Pediatr. 2019 May 10;7:178. doi: 10.3389/fped.2019.00178.

3. Larkins N, Kim S, Craig J, Hodson E. Steroid-sensitive nephrotic syndrome: an evidence-based update 
of immunosuppressive treatment in children. Arch Dis Child 2016; 101(4), 404-408. 10.1136/archdischild-2015-308924

4. Zagury A, de Oliveira AL, de Moraes CAP, de Araujo Montalvão JA, Novaes, RHLL, de Sá VM, et al. Long-term follow-up after cyclophosphamide therapy in steroid-dependent nephrotic syndrome. Pediatr Nephrol, 2011;26(6): 915-920.

5. Durkan A, Hodson E, Willis N, Craig J. Non-corticosteroid treatment for nephrotic syndrome in children. Cochrane Database Syst Rev 2001;(4):CD002290. doi: 10.1002/14651858.CD002290.

6. Nandi M, Mandal S, Samanta M, Majhi A, Das M. Efficacy of mycophenolate mofetil as a remission maintaining agent in idiopathic childhood nephrotic syndrome. Indian J Nephrol. Indian J Nephrol. 2019. PMID: 30814791

7. Fu H-D, Qian G-L, Jiang Z-yang. J Investig Med Published Online First: [please include Day Month Year] doi:10.1136/jim-2016-000163

8. Tarshish P, Tobin JN, Bernstein J, et al. Prognostic significance of the early course of minimal change nephrotic syndrome: report of the International Study of Kidney Disease in Children. J Am Soc Nephrol 1997;8:769-76.

9. Koskimies O, Vilska J, Rapola J, et al. Long-term outcome of primary nephrotic syndrome. Arch Dis Child 1982;57:544-8.

10. Durkan AM, Hodson EM, Willis NS, Craig JC. Immunosuppressive agents in childhood nephrotic syndrome: a meta-analysis of randomized controlled trials. Kidney Int 2001;59:1919-27.

11. Hodson EM, Willis NS, Graig JC. Non-corticosteroid treatment for nephrotic syndrome in children. Cochrane Database Syst Rev 2008;(1):CD002290.

12. Larkins NG, Liu ID, Willis NS, CraigJC, Hodson EM. Non-corticosteroid immunosuppressive 
medications for steroid-sensitive nephrotic syndrome in children. Cochrane Database Syst Rev. 2020 Apr 16;4(4):CD002290.

13. Tan L, Li S, Yang H, Zou Q, Wan J, Li Q. Efficacy and acceptability of immunosuppressive agents for pediatric frequently-relapsing and steroid-dependent nephrotic syndrome A network meta-analysis of randomized controlled trials. Medicine 2019;98:22 (e15927). doi.org/10.1097/MD. 0000000000015927

14. Pravitsitthikul N, Willis NS, Hodson EM, CraigJC, Hodson EM. Non-corticosteroid immunosuppressive medications for steroid-sensitive nephrotic syndrome in children. Cochrane Database Syst Rev 2013; (10):CD002290.

15. Kemper MJ, Valentin L, van Husen M. Difficult-to-treat idiopathic nephrotic syndrome: established drugs, open questions and future options. Pediatr Nephrol. 2018; 33(10): 1641-1649. $10.1007 / \mathrm{s} 00467-017-3780-7$

16. Nandi M, Mandal S, Samanta M, Majhi A, Das M. Efficacy of mycophenolate mofetil as a remission maintaining agent in idiopathic childhood nephrotic syndrome. Indian J Nephrol. 2018;10.4103/ijn.IJN_330_17

17. Wang J, Mao J, Chen J, Fu H, Shen H, Zhu X, et al. Evaluation of mycophenolate mofetil or tacrolimus in children with steroid sensitive but frequently relapsing or steroid-dependent nephrotic syndrome. Nephrology, 2016; 21(1): 21-27. 10.1111/nep.12537 